\title{
A ENGRENAGEM DA PRODUÇÃO DE FRUTAS: Estado, empresários e trabalhadores no Vale do São Francisco
}

\author{
THE FRUIT PRODUCTION GEAR: \\ State, businessmen and workers in the San Francisco Valley
}

\author{
José Fernando Souto JR
}

\begin{abstract}
Resumo
Este trabalho é uma tentativa de entender a construção do "modelo de desenvolvimento" no Submédio Vale do São Francisco, destacando a constituição e contribuição dos diversos atores sociais envolvidos. O trabalho é resultado de dois projetos de pesquisa realizados com apoio do CNPq entre 2010 e 2014 . Durante esse período, foram realizadas 17 entrevistas com roteiro semiestruturado com lideranças do movimento sindical dos trabalhadores, empresários, assessores jurídicos e representantes de agências diversas do Estado. Também foram pesquisados documentos em diversos arquivos privados nas cidades de Petrolina (PE) e Juazeiro (BA). O método da pesquisa e o tratamento de análise dispensado ao con-junto de documentos foi o qualitativo e o artigo está estruturado em três partes: o contexto de surgimen-to do Vale como produtor de hortifrutigranjeiros, resultado direto da ação empreendedora e indutora do Estado; a segunda parte ressalta que o êxito do modelo teve como característica uma ação empresarial induzida e estimulada pelas agências federais, a organização do empresariado em cooperativas e asso-ciações que desenvolveram o know-how empregado na exportação de frutas, ao mesmo tempo em que se tornaram atores políticos importantes junto às diversas esferas de governo; por fim, a incorporação dos trabalhadores como elemento fundamental para garantir consenso ao modelo e, por consequência, previsibilidade ao processo de produção.

Palavras-chave: Desenvolvimento. Sindicatos. Trabalhadores. Empresários.
\end{abstract}

\begin{abstract}
This work is an attempt to understand the construction of the 'development model' in the Submedia of the São Francisco Valley highlighting the constitution and contribution of the various social actors in-volved. The work is the result of two research projects carried out with the support of CNPq between 2010 and 2014. During this period, 17 interviews were conducted with a semistructured itinerary with leaders of the trade union movement of workers, businessmen, legal advisors and representatives of various agencies of the State. Also, documents were searched in several private archives in the cities of Petrolina - PE and Juazeiro - BA. The method of research and the treatment of analysis given to the set of documents was qualitative and the article is structured in three parts: the context of the emergence of the Valley as producer of horticultural crops, a direct result of the entrepreneurial action and inducing the State; the second part highlights that the success of the model had as a characteristic a business action induced and stimulated by the federal agencies, the organization of the business in cooperatives and associations that developed the know-how used in the export of fruits, at the same time they became actors important politicians at the various levels of government; Finally, the incorporation of the workers as a fundamental element to guarantee consensus to the model and, consequently, predictability to the production process.
\end{abstract}

Keywords: Development. Unions. Workers. Businessmen.

\section{Introdução}

O Submédio Vale do São Francisco (SMSF) tem se notabilizado pela produção de frutas para exportação. Segundo números da Associação dos Produtores e Exporta-dores de Hortifrutigranjeiros e Derivados do Vale do São Francisco (Valexport), a área irrigada do Vale

\footnotetext{
* Entre 2015-2016, desenvolveu estágio pós-doutoral na University of Sussex pesquisando a fruticultura irrigada do Vale são Francisco. Atualmente é Professor Associado II de Sociologia na Universidade Federal do Vale do São Francisco. E-mail: fsoutojr@hotmail.com
} 
era de 360.000 hectares em 2013; a região é a terceira maior produtora de frutas do mundo, produzindo 43,8 milhões de toneladas por ano. O consumo mundial de frutas frescas é da ordem de 42 milhões de toneladas por ano, movimentando US\$ 28 bilhões anualmente, a participação do Brasil, por sua vez, é da ordem de US\$ 642,7 milhões (2,3\%). Desse total, o SMSF participa com 39,1\%, exportando principalmente uva e manga, sendo responsável por um total de US\$251,5 milhões. $80 \%$ da uva e $65 \%$ da manga exportadas pelo SMSF vão para a União Europeia; $15 \%$ da uva e 30\% da manga vão para os Estados Unidos e os 5\% restantes de manga e uva vão para o Canadá, países da Ásia, da América do Sul e do Oriente Médio (VALEXPORT, 2013).

A magnitude dos negócios no SMSF foram a motivação para as pesquisas que desenvolvemos desde 2008, financiadas por fundações de amparo à pesquisa: Facepe, Fapesb, Cnpq e Capes. Ao longo desse tempo, foram publicados vários artigos, que são citados ao longo do corpo desse trabalho. Foram 17 entrevistas semiestruturadas, visitas regulares aos arquivos privados dos sindicatos dos trabalhadores rurais, dos jornais locais e das bibliotecas das universidades localizadas entre Petrolina e Juazeiro, além da Embrapa, com o objetivo de procurar documentos relacionados à fruticultura irrigada. Optou-se desde o início pelo método qualitativo, objetivando aprofundar a compreensão da ação dos atores sociais nesse estudo de caso (FLICK, 2009; GOLDENBERG, 2004) e fazendo uso da análise documental (PIMENTEL, 2001; CELLARD, 2010).

No decorrer das pesquisas, identificamos publicações que são referências para se pensar o desenvolvimento da fruticultura irrigada no SMSF. São publicações recorrentemente citadas em artigos acadêmicos e alguns dos autores orientaram trabalhos acadêmicos diversos sobre esse tema. Assim, desde o livro-denúncia de Bloch (1996), aos trabalhos acadêmicos de Cavalcanti (1996, 1997, 2003), Daminani (1999), Silva (2001, 2009) e Selwyn (2008, 2009, 2010), todos podem ser considerados fundamentais para o entendimento da fruticultura do SMSF.

Nos escritos desses autores, encontramos a convergência de cinco dimensões de análise que nos ajudaram a caracterizar o que chamamos de "modelo de desenvolvimento" no SMSF, com características de um cluster. Essas dimensões se articulam numa perspectiva teórica formando uma unidade, como demonstraremos mais à frente, ao mesmo tempo em que são passíveis de verificação empírica separadamente. Elas estão interligadas diacronicamente e se caracterizam por uma complexa teia de relações edificada sobre a proeminência do Estado a) grandes investimentos em infraestrutura do governo federal e b) pela constituição de agências estatais com a tripla missão de pensar, promover e viabilizar o desenvolvimento econômico, transformando uma vasta área de terras secas do semiárido em terras irrigadas; c) uma iniciativa privada filha caudatária dos planos e projetos elaborados sob as hostes de um corpo técnico de servidores de agências estatais como Sudene, Banco do Nordeste, Codevasf, Embrapa etc.; aliada d) ao papel desempenhado nesse processo pelas organizações de interesses empresariais, caracterizadas pela ação coletiva e pelo associativismo de cooperativas e associação do 
empresariado; e, por fim, e) à incorporação dos trabalhadores, por meio de um compromisso negociável anualmente com os empresários e mediado pelo Estado.

Assim, o que chamamos de "modelo de desenvolvimento" é a articulação das dimensões apontadas acimas e que serão desenvolvidas abaixo. A articulação das cinco dimensões se configura no que Porter define como cluster:

\begin{abstract}
Clusters are geographic concentrations of interconnected companies and institutions in a particular field. Clusters encompass an array of linked industries and other entities important to competition. They include, for example, suppliers of specialized inputs such as components, machinery, and services, and providers of specialized infrastructure. Clusters also often extend downstream to channels and customers and laterally to manufacturers of complementary products and to companies in industries related by skills, technologies, or common inputs. Finally, many clusters include governmental and other institutions - such as universities, standards-setting agencies, think tanks, vocational training providers, and trade associations - that provide specialized training, education, information, research, and technical support (PORTER, 1998, p. 3).
\end{abstract}

Na configuração do cluster no SMSF, há uma predominância clara do papel do Estado nas dimensões enumeradas: na definição da área e da construção de toda a infraestrutura, na criação das agências que definiram as diretrizes e executaram os planos para o desenvolvimento, na criação de agência de pesquisa, universidades, no direcionamento dos recursos de pesquisas, no estímulo ao cooperativismo e ao associativismo da iniciativa privada e, por fim, na fiscalização das condições de trabalho.

Foi com a antropologia do desenvolvimento de Sardan (2005) que encontramos a ferramenta para auxiliar na compreensão da constituição desse modelo. Partindo do dissenso, é possível entender as estratégias dos atores. Sardan trata de três perspectivas, que absorve de Gluckman. Em primeiro lugar, toda sociedade é atravessada por conflitos, em segundo, conflitos são indicativos de variedades de posicionamentos sociais e, assim sendo, são expressões de interesses ligados às diferentes posições sociais (dos atores) e são estruturados culturalmente. Por fim, os conflitos, para além de uma interpretação de que eles conduzem ao caos, contribuem ao menos para a sua reprodução ao reforçar a coesão social (SARDAN, 2005).

Articulando as dimensões do "modelo de desenvolvimento" com o conceito de arena de Sardan: "the arena is basically the social space in which these confrontations and competitions occur" (2005, p. 189), procura-se visualizar os posicionamentos dos agentes em interação e o desvelamento de suas estratégias em confronto como lógicas entrelaçadas, "como um campo social que coloca em relação, com uma intensidade particular, atores diversos, interesses heterogêneos, lógicas de ação plurais e universos simbólicos divergentes" (BIERSCHENCK apud CARNEIRO, 2012, p. 134). Buscar articular essas dimensões citadas acima e articulá-las com o conceito de arena é o objetivo desse trabalho. 


\section{Dissecando o modelo: o Estado, o semiárido, a irrigação e as agências de desenvolvimento}

Foi o direcionamento efetivo de políticas do governo federal, com o objetivo de suprir a demanda por alimentos das regiões metropolitanas do Nordeste, que permitiu a retirada do Semiárido nordestino do isolamento político e econômico tornando-o produtor de alimentos (OLIVEIRA, 1981). A atenção para com o Nordeste teve início com o Departamento Nacional de Obras Contra as Secas (DNOCS) em 1909. Foi a primeira agência do Estado a estudar a problemática do Semiárido.

Os grandes investimentos iniciaram nos anos de 1945 com a criação da Companhia Hidroelétrica do São Francisco. Com o objetivo de aproveitar as águas do São Francisco para gerar energia, as obras para construção de lagos e usinas vieram acompanhadas de obras de infraestrutura que beneficiaram a região. Com a instituição da Comissão do Vale do São Francisco (CVSF), em 1948, o governo federal passou a enxergar o SMSF com base em suas peculiaridades geográficas e climáticas, encomendando as primeiras pesquisas para as culturas irrigadas e o apoio técnico aos colonos. Mas foi com o Grupo de Trabalho Para o Desenvolvimento do Nordeste e, posteriormente, com a Superintendência de Desenvolvimento do Nordeste (Sudene), em 1959, que surgiram as primeiras propostas associadas a um plano extenso de irrigação. Dentro de um conjunto de políticas direcionadas ao Nordeste e ao SMSF, a irrigação tornou-se uma alternativa viável, tendo em vista o caso exitoso de Israel. Em 1963, foi instituído o Grupo de Irrigação do São Francisco e foram criadas duas estações experimentais ${ }^{1}$.

A Sudene, em parceria com a Food Agricultural Organization, em 1966, realizou o levantamento pedológico das áreas irrigáveis e definiu o Plano Diretor da Irrigação (PDI). Tendo em vista a mudança de atenção que a região recebia, a CVSF foi transformada em Superintendência do Vale do São Francisco (Suvale), que assumiu a execução do PDI, ao mesmo tempo em que foi responsável por obras de infraestrutura, como rodovias, escolas e a construção do aeroporto de Petrolina, em 1958.

Foi em 1974 que a Suvale foi transformada em Companhia de Desenvolvimento do Vale do São Francisco (Codevasf). Para Silva (2001) e Damiani (1999), o marco decisivo da irrigação e do êxito da fruticultura irrigada é da Codevasf, que elaborou e implementou políticas estruturais, pondo fim às políticas setorizadas e descontínuas de diversas agências do Estado. Inicialmente, ela teve o papel de acompanhar todas as fases dos projetos de irrigação, desde a avaliação de viabilidade técnica até a econômica. Foi responsável pela implantação, acompanhamento e desenvolvimento de cada projeto. Segundo Damiani, a forma singular de atuação garantiu o sucesso do polo Petrolina-Juazeiro. A boa performance pode ser explicada pela aplicação de princípios inovadores na gestão dos projetos, dividindo a área entre pequenos e médio produtores e grandes empresas, introduzindo uma competição por subsídios direcionados, o

1 Anos mais tarde, essas estações experimentais se transformaram nos projetos pilotos de Bebedouro, criado em 1968 na cidade de Petrolina (PE), e no projeto Mandacaru, entre 1971 e 1972, na cidade de Juazeiro (BA). 
que demandou melhor performance das empresas, ao mesmo tempo em que o turnover nos projetos colaborou para a substituição de empresas menos competitivas (DAMIANI, 1999).

Os projetos capitaneados pela Codevasf visavam alavancar a economia local pelo casamento da produção agrícola com a indústria. No modelo agroindustrial, coube às grandes empresas a geração de empregos e divisas, e em razão da sua capacidade de investimento e da otimização do capital, elas produziriam usando tecnologias modernas, que seriam difundidas junto aos médios e pequenos produtores, aperfeiçoando o uso do solo e da água: "in the mid1970s, CODEVASF started to organize workshops in São Paulo and Rio de Janeiro in which it presented complete information to potential investors about its irrigation projects" (DAMIANI, 1999, p. 35). O Banco do Nordeste do Brasil (BNB) e a Sudene abriram linhas de crédito para atrair e financiar a agroindústria. "O sentido fundamental dessas políticas era, portanto, articular a modernização agrícola com a constituição de um polo agroindustrial" (SILVA, 2001, p. 83). Avançando na política de tornar o SMSF um polo agroindustrial, em 1975, foi criado o Centro de Pesquisa Agropecuária do Trópico Semiárido (CPATSA-Embrapa). Em 1976 foi estabelecido um convênio entre a Codevasf e a Embrapa, que assumiu a manutenção e a operacionalização das estações experimentais de Bebedouro e Mandacaru, viabilizando as pesquisas e o desenvolvimento de frutas e hortaliças (SILVA, 2001).

Apesar de inicialmente o polo agroindustrial ter obtido êxito, principalmente na produção de derivados de tomate e de suco, alguns fatores levaram à sua decadência. No caso do tomate, a ausência de um planejamento adequado entre a indústria e os agricultores no período da colheita, impediu o processamento de grandes quantidades do tomate. Além disso, problemas relacionados aos preços do tomate, levaram os agricultores ao endividamento. Por fim, a praga que atacou esse fruto colocou um fim na agroindústria (DAMIANI, 1999; SILVA, 2001, 2009).

A passagem para a fruticultura se deu com a crise da agroindústria e da agricultura irrigada tradicional, que cedia lugar à expansão da fruticultura. A uva foi o carro chefe e nos anos 1980 continuava atrelada à vinicultura, na perspectiva da agroindústria. Para Silva, "a produção de frutas para o mercado de exportação in natura significa um rompimento com a lógica prevalecente de agroindustrialização". Foram os empresários que compreenderam o fracasso do polo agroindustrial e enxergaram na fruticultura uma alternativa, contrariando "as ideias arraigadas nos organismos públicos que insistiam na formação do complexo agroindustrial, sem vislumbrar a alternativa da fruticultura para o mercado in natura, que já tinha uma certa expressão na região" (2001, p. 94-95). O papel da Embrapa foi decisivo, já que o conhecimento que se desenvolvia nos projetospilotos servia também como vitrine viva das possibilidades reais da fruticultura.

Em 1987, iniciariam os esforços para as primeiras exportações. No entanto, durante a década de 1990, o governo iria mudar sua forma de intervenção no SMSF. No ano de 1996, o governo lançou o Programa de Apoio e Desenvolvimento da Fruticultura Irrigada do Nordeste 
(PADFIN), que enfatizava uma mudança no tipo de intervenção, como as demais políticas públicas desse período, rejeitava o papel interventor do Estado e a irrigação deveria funcionar de acordo com a lógica do mercado.

Segundo Selwyn (2010), a implantação dos projetos de irrigação obedeceu a três fases: na primeira, entre o final dos anos 1960 e 1970, foram distribuídos pequenos lotes para poucos colonos e o tipo de agricultura utilizava tecnologia elementar de irrigação para produzir gêneros alimentícios para o consumo e venda. A segunda fase, do final dos anos 1970 até meados dos anos 1990, caracterizou-se pela ação da Codevasf de construir novos distritos de irrigação com um amplo programa de extensão rural e assistência técnica, subsidiando água e energia, disponibilizando as terras não apenas para os novos colonos, que receberam lotes de 06 a 12 hectares, mas também para empresas, que receberam lotes entre 50 e 100 hectares. A terceira fase, situada entre meados dos anos 1990 em diante, caracterizou-se pela retirada gradual da assistência técnica, o aumento de ênfase para o setor privado, em termos de introdução de novos cultivos, conhecimento e conexões de marketing e alocação da terra, antes voltada para pequenos colonos com pouco ou nenhum capital, para pequenos e médios colonos relativamente bem capitalizados e para grandes investidores. Os programas de extensão rural e assistência técnica ficaram apenas para os antigos colonos (SELWYN, 2010).

A política federal de ação no semiárido produziu diversas formas de intervenção e múltiplas agências estatais. O desenvolvimento do Vale foi baseado nos mega projetos de infraestrutura, como as hidroelétricas, depois a irrigação, da agroindústria à fruticultura. Desde meados dos anos 1940, a política intervencionista sofreu modificações de acordo com os credos políticos dominantes. Da fase em que a intervenção foi direta, no período do Estado empreendedor, até a política dos anos 1990, de orientação neoliberal, em que a indução do desenvolvimento privilegiou a iniciativa privada como ator estratégico.

É de se notar o protagonismo do Estado ao agir diretamente para tirar o SMSF do isolamento político e econômico, desde os grandes projetos para gerar energia, que se tornaram a base para os futuros projetos de irrigação. Mas até que ponto o protagonismo do Estado geraria uma iniciativa privada dependente? Qual o alcance das ações do Estado para estimular o desenvolvimento de uma iniciativa privada dinâmica no sertão nordestino? De que maneira a iniciativa privada assumiria o protagonismo?

\section{O Estado criando um ator político: as organizações de interesses dos produtores}

A decisão de incorporar à discussão as organizações de interesses empresariais está associada ao fato de que, dentro da perspectiva do dissenso proposta por Sardan, as associações empresariais representariam a forma articulada de interesses que disputariam espaço na arena, compreendendo esta como o projeto de desenvolvimento: 
[o conceito de arena] Evoca, ao mesmo tempo, uma escala mais restrita e uma consciência mais clara dos enfrentamentos por parte dos atores. Uma arena, no sentido que nós a entendemos, é um lugar de confrontações concretas de atores sociais em interação acerca de questões comuns. Ela se refere a um espaço "local". Um projeto de desenvolvimento é uma arena. [...]. (SARDAN apud CARNEIRO, 2012, p. 143).

A racionalidade do capital, incorporada pelos técnicos da Codevasf, indicava que o desenvolvimento do SMSF não aconteceria se não houvesse uma iniciativa privada com maior dinamismo. Após todo o investimento estatal e algumas experiências fracassadas, como a do melão, por exemplo, ficou claro que seria necessário estimular uma dinâmica empresarial com uma racionalidade menos dependente do Estado e capaz de assumir mais riscos. Mas como fazê-lo?

A estratégia foi recrutar produtores com expertise em exportação e cooperativismo. O marco decisivo foram os anos 1970, quando a Codevasf convidou a Cooperativa Agrícola de Cotia e ofereceu terras para produzirem nos projetos irrigados. Direcionada pelo Estado, essa política de recrutamento de novos colonos tinha dois objetivos: trazer novos colonos para ocupar terras ociosas e introduzir um tipo especifico de colono com perfil voltado para a forma associativa do cooperativismo e com uma racionalidade empresarial mais agressiva, capaz de liderar o projeto de desenvolvimento no momento em que o Estado se preparava para deixar algumas de suas atribuições.

O desdobramento dessa inciativa se deu com a aliança formada entre a Codevasf e a Cotia (esse perfil empreendedor foi recrutado no Sudeste), a maior cooperativa agrícola do país com mais de 200 escritórios no Brasil, inclusive em Juazeiro, onde comprava melões para vender nos mercados do Sudeste e nas capitais nordestinas. A ideia inicial visava atrair empresas com reconhecida experiência em exportação e comprovado conhecimento das exigências do mercado externo. A Cotia era a escolha óbvia, com reconhecido know-how na exportação de produtos agrícolas desde os anos 1960 e com escritório em Rotterdam. Colonos ligados à cooperativa se estabelecerem em Curaçá (BA), no SMSF, para produzir melão. Ao longo do tempo, o Vale passou a ser o maior exportador de melão do país e a Cotia a principal exportadora (DAMIANI, 1999).

A visão empresarial do grupo de produtores ligados à Cotia deve ser observada a partir de sua relação com a terra, que deixava de ser vista apenas como agricultura e passava a ser vista como agrobusiness, uma expressão carregada de valores empresariais para os negócios no campo, significando uma relação mais complexa com os mercados interno e externo. Para Mendonça, o patronato rural moderno é oriundo das cooperativas, defende a autogestão, representa a modernização no campo, e é deles o termo agronegócio, concepção que relaciona todas as atividades econômicas ligadas direta ou indiretamente à agricultura - constituindo-se num "poderoso complexo, de cunho bem mais comercial e financeiro, cujo peso não poderia 
ser aquilatado apenas por seu desempenho econômico, mas principalmente por sua influência política” (MENDONÇA, 2010, p. 219).

A expertise da Cotia serviria de modelo para expandir o leque de frutas no exterior. Uma série de problemas foram sanados com o conhecimento já acumulado pela Cotia, facilitando as tarefas relacionadas à exportação, como o entendimento das normas sobre os padrões de qualidade requeridos no mercado de frutas frescas. A coordenação do processo de produção e de distribuição dos fruticultores teve efeito eficaz nos seguintes itens: evitou a concentração das colheitas e viabilizou as fases relacionadas à embalagem, armazenamento e transporte das frutas; garantiu maior eficácia no controle sobre as pragas; e a ampla rede de relações com compradores internacionais da Cotia ajudou a resolver um dos principais entraves, o de marketing (DAMIANI, 1999; SILVA, 2001; GOMES, 2004; SELWYN, 2008, 2010).

$\mathrm{O}$ exportador necessita coordenar um grande número de tarefas. Diferente da maioria dos produtos manufaturados, frutas são mercadorias perecíveis e não podem ser estocadas por longo tempo sem perder qualidade e valor. Portanto, elas devem estar disponíveis para o consumidor em duas ou três semanas após a colheita. Qualquer atraso envolve perdas na qualidade e nos preços. Para evitar atrasos, os fruticultores necessitam ter disponíveis: trabalho para a colheita, embalagens e condições seguras de armazenagem e transporte (DAMIANI, 1999; SOUTO JR, 2013).

Os países compradores impõem exigências que afetam as técnicas de produção, de modo que as frutas estejam dentro de especificações técnicas que atendam a legislação de cada país. Por outro lado, estas exigências estão relacionadas ao marketing, que padroniza os produtos definindo os elementos estéticos como tamanho, cor do fruto, forma da embalagem, além dos elementos de composição do sabor, como a quantidade mínima de água e açúcar (CAVALCANTI, 1997; SELWYN, 2008).

O processo de produção é afetado desde a preparação da terra, que está relacionada aos produtos adequados e à aplicação correta dos insumos no tratamento das plantas, como adubos e pesticidas, até o pós-colheita, com a classificação dos frutos, a embalagem, o armazenamento e o transporte (terrestre, marítimo e aéreo). Essa gama de tarefas não poderia ser realizada pelos diversos produtores sem que houvesse organizações que as coordenassem. Parte desse papel foi desenvolvido com êxito pelas cooperativas, que propagaram uma mentalidade empresarial e de autogestão.

A Codevasf ajudou a fomentar uma associação de produtores. Desse esforço nasceu, em 1988, a Associação dos Produtores e Exportadores de Hortifrutigranjeiros e Derivados do Vale do São Francisco - Valexport. Em entrevista à pesquisa, José Gualberto de Freitas narrou como se deu a ideia inicial para a criação da associação. Em sua versão do surgimento da Valexport, não havia um protagonismo da Codevasf, mas uma ideia que surgiu com o empresariado local. Responsável pela Fazenda Milano, primeiro grande projeto de irrigação de fruticultura, que se dedicou à produção de uva e vinho, Gualberto foi um dos empresários pioneiros do SMSF: 
Nós começamos a ver que o mercado interno era insuficiente e os perímetros da Codevasf, principalmente aqueles que a Codevasf administrava diretamente, ou estavam ineficientes ou estavam pouco ocupados, como era o Projeto Curaçá, o Projeto Maniçoba - na Bahia - o Massangano, que hoje é o Nilo Coelho. Percebeu-se uma necessidade de se trabalhar esse setor com maior eficiência. E aí coincidiu de o governo Sarney, que o presidente da Embrapa foi deslocado para a presidência da Codevasf, Dr. Eliseu Alves... e então numa visita dele aqui na região, até com o presidente da república, eu tive oportunidade de conhecê-lo... então conversando com ele, chegamos ao mesmo diagnóstico, precisaria ter alguma coisa pra organizar aí essa produção e melhorar a qualidade média de todos, não só nossa mas dos pequenos e médios, e então concordamos em criar uma organização... então ele disse: "eu apoio, nós vamos lhe apoiar, organize aí alguns produtores, e eu lhe dou um apoio institucional. A Codevasf vai lhe dar um apoio institucional"'.

No livro Prosa com Eliseu, entrevista a Jorge Duarte, Eliseu Alves assim descreveu sua trajetória na Codevasf:

Para garantir a exportação de frutas, o senhor juntou vendedores e compradores.

Lá por volta de 1988, mandei, daqui para a Europa, uns 40 produtores de frutas do Semiárido. Arranjei dinheiro, coloquei o pessoal dentro do avião, e eles foram para a Holanda.

\section{E o resultado?}

Deu certo, o negócio estava maduro. Não foi mérito meu; os outros é que deixavam de enxergar isso. Criamos uma associação de irrigan- tes para administrar cada projeto e também a associação de exportadores. E ainda mudamos a lei de irrigação. Tudo isso nos 5 anos que fiquei lá na Codevasf.

\section{O que foi alterado na lei?}

A ideia básica era dar mais poderes aos agricultores (DUARTE, 2018, p. 127).

Ainda em 1986, a Codevasf montou uma força tarefa para promover e viabilizar a exportação de frutas, realizando workshops com especialistas estrangeiros que trataram de temas como: as regras dos mercados internacionais, as imposições governamentais para exportação de alimentos e frutas frescas, as questões de marketing e as exigências dos mercados etc. No ano seguinte, convidou os principais produtores de frutas e alguns políticos para discutir a exportação de frutas e identificar as ações das agências do governo federal com o objetivo de resolver os gargalos para exportação.

Para Damiani, uma das estratégias de sucesso da Codevasf foi estimular o engajamento local dos produtores para construir, via iniciativa privada, instituições de cooperação nas quais os fruticultores poderiam resolver de forma coletiva seus problemas, como a complexidade e o alto custo das tecnologias para exportar frutas. Problemas encontrados na qualidade das frutas

2 Entrevista com José Gualberto de Freitas Almeida, liderança empresarial, realizada em Santa Maria da Boa Vista, em 15 de fevereiro de 2019. 
são passíveis de penalidades nos preços e, geralmente, impedem novas entradas nos mercados externos.

CODEVASF pushed firms very strongly to organize themselves, arguing that they needed an association for at least the following powerful reasons: a) to collect information and search for export markets; and b) to press the federal government to carry out policies and other interventions that helped producers of fruits for export, such as investing in improving the Suape harbor and the highway between Petrolina and Suape, and increasing the funding for research on export crops available to the EMBRAPA research station in Petrolina. CODEVASF also argued that if firms jointly contracted transportation by trucks and ships, they would save substantial amounts of Money (DAMIANI, 1999, p. 49).

O alcance da atuação da Valexport pode ser vista nos documentos da própria associação já depois de formada.

A VALEXPORT foi criada em 1988 com o objetivo de representar o empresário hortifrutigranjeiro local de forma institucional, intervindo junto aos poderes públicos constituídos, sejam eles nacionais ou internacionais. (...) Manter relacionamentos e firmar convênios com órgãos, entidades e empresas públicas ou privadas, no país e no exterior, que exerçam atividades relacionadas com a produção, preparação, transporte, armazenamento, comercialização, exportação e promoção de produtos hortigranjeiros no Brasil e no exterior, em todas as formas, inclusive através de participações em feiras, exposições, com fundos próprios ou de terceiros (VALEXPORT, 2014, p. 6).

A Codevasf apoiou a criação da associação custeando as despesas com o aluguel, equipamentos e mobiliário, pagou o salário de um técnico para administração por um ano, desenhou os estatutos, contratou estudo sobre viabilidade de exportação de frutas e vegetais para Europa e divulgou as frutas do SMSF em feiras da Europa.

A Cotia desempenhou um papel diretivo nesse processo ao ensinar como exportar, deslocando diretores de sua área de exportação em São Paulo para o SMSF e pagando seus salários até que a Valexport pudesse contratá-los. O objetivo da associação não foi apenas atuar na diminuição dos custos de produção, mas monitorar e aferir o controle de qualidade das frutas de seus associados que deveriam ser exportadas.

Em 1994, a Cotia faliu, mas cumpriu com a sua missão de transformar mentalidades. Os fatos decorrentes após a decretação da falência expressaram o alcance da autogestão, fato também decisivo para a configuração do espírito de cooperação de um cluster, que promove a competição com a cooperação. Os rivais competem intensamente por consumidores. Sem uma vigorosa competição, o cluster pode falir. Por isso a necessidade de cooperação. A competição pode existir com cooperação porque ocorre em diferentes dimensões entre diferentes players (PORTER, 1998).

Frustrados com a falência, fruticultores fundaram a Cooperativa Agrícola de Juazeiro (CAJ), que implantou um novo modelo de gestão, tornando o processo de decisão mais próximo 
dos cooperados, centralizando o processo de compra de insumos e a venda da produção, tratando da padronização dos processos e procedimentos de produção - pós-colheita, embalagem, resfriamento e transporte - e criando uma marca própria para exportação de frutas, a Copacabana Gold (SILVA, 2001).

Em 1992, membros da Valexport formaram um grupo interno e criaram a Brazilian Grapes Marketing Board (BGMB), cuja presidência ficou a cargo da CAJ. O BMGB funcionou como uma marca própria, os fruticultores deveriam manter um controle de qualidade rigoroso na produção, que seria auditado mensalmente. A BGMB estimulava os pequenos produtores a formarem associações para ingressarem no board, tal medida os ajudava no aumento de serviços compartilhados e diminuía os custos tarifários relacionadas à exportação (SELWYN, 2008, 2013).

As atribuições da Valexport estão relacionadas a sua estrutura interna, que são várias, mas aqui cabe tratar de um ponto específico: as Convenções Coletivas de Trabalho (CCT). Fruticultores e trabalhadores do SMSF se reúnem e definem uma convenção de trabalho definindo regras, benefícios e salários, tendo a Valexport como coordenadora do evento, com a mediação das Gerências Regionais do Trabalho e Emprego nas cidades de Juazeiro e Petrolina (VALEXPORT, 2014).

Outra de suas atribuições é a organização do pool de fretes marítimos, "tem como principal tarefa a organização dos volumes a serem exportados em navios, a consolidação da carga, a contratação dos armadores e dos operadores portuários" (SILVA, 2001, p. 136). Assim, a Valexport se legitimou como ator político entre os produtores ao tornar-se o elo entre os fruticultores e os compradores externos, ao mesmo tempo, assumiu o papel de fiadora da qualidade dos frutos para os mercados internacionais, ao auditar a qualidade da produção dos seus associados.

Por outro lado, a Valexport transformou-se num ator político importante, agregando os interesses dos fruticultores do SMSF e estendendo sua área de influência. Em 1995, junto com a associação dos produtores de frutas do Sul do país, criou o Instituto Brasileiro de Frutas (IBRAF), que se tornou a organização mais importante para os exportadores. Um membro da Valexport participou como representante do setor privado nas negociações de diminuição de tarifas em reuniões do Mercosul. Em 1996, foi parte integrante do Conselho da Autoridade Portuária, sugerindo melhoras para os portos. Já em 1996 e 1997, pressionou parlamentares no Congresso Nacional para incluírem verbas para a construção de uma estrada de ferro entre Recife e Salgueiro e convenceu o Ministério da Agricultura a designar um representante da associação para participar do Conselho de Pesquisa da Embrapa. Além disso, participou da Comissão Nacional da Fruticultura da Confederação Nacional da Agricultura (CNA) e do Conselho Nacional de Pesquisa (CNPq) (DAMIANI, 1999; SILVA, 2001).

Aristeu Chaves foi um dos pioneiros na produção de manga no SMSF e fundador da Valexport. Em seu depoimento, ficam claras as articulações da associação. 
Primeiro você fazia o projeto. A Embrapa do Vale competia com a Embrapa de São Paulo. Cada um queria desenvolver, ter mais pesquisa em sua Embrapa, no Semiárido, etc... Nós éramos parceiros ali... a gente chegava lá no Ministério da Agricultura, a Associação de Produtores e a Embrapa alinhada e dalí a gente ia pra demanda, ia pra o setor competente, que tinha uma lista de mil pedidos também. Aí a gente ia bater na porta dos políticos, ia pra vice-presidência de Marco Maciel, ia pra parte da Bahia, ia pra o Osvaldo Coelho ${ }^{3}$.

A atuação da Valexport revela que a associação se tornou um ator importante, um player capaz de influenciar as políticas públicas do Estado, ao organizar, coordenar e canalizar as demandas do empresariado para dentro das engrenagens estatais, fazendo-as se moverem em seu favor pelo seu poder de lobby. $\mathrm{Na}$ arena de disputas em torno do projeto de desenvolvimento, tornou-se, nos anos 1990 e 2000, o principal player a pintar e ordenar os caminhos do desenvolvimento, tanto no ambiente privado quanto no espaço público.

\section{A peça que faltava: a inclusão dos trabalhadores}

O êxito da fruticultura não poderia deixar de fora a força de trabalho. Tal intento tem sido prejudicado por não haver números confiáveis com relação ao tamanho da força de trabalho na fruticultura. Assim, autores trabalharam com números diversos de fontes que tratam de assuntos diferentes, como a Relação Anual de Informações Sociais (RAIS) e o Cadastro Geral de Empregados e Desempregados (CAGED), o Censo agropecuário do IBGE, informações da Codevasf e dos sindicatos de trabalhadores rurais. Os números mais gerais de empregos gerados pela fruticultura irrigada impressionam. Segundo a Valexport: "estima-se que são gerados em média 2,0 empregos por hectare irrigado, gerando um total de 240.000 empregos diretos e 960.000 empregos indiretos" (VALEXPORT, 2014, p. 3). A Associação Comercial Industrial e Agrícola de Juazeiro trabalha com números semelhantes. Não há clareza de como chegaram a estes números.

Os dados estatísticos oficiais como o Censo Agropecuário, os dados da RAIS e o CAGED têm limitações por levar em consideração apenas os vínculos formais e, em alguns casos, não levar em conta as contratações sazonais, ocorridas em épocas de safra, que, segundo estimativas, aumentam consideravelmente o total da força de trabalho durante os meses de colheita. Alguns autores trabalharam com margens diferentes, que vão de 20 mil para alguns, enquanto outros optam por 40 mil e até 60 mil. Os autores tendem a acreditar que os números de trabalhadores permanentes estejam entre 50\% e 60\% do total da força de trabalho (SOUTO JR; MOTA SILVA; ALMEIDA, 2015).

Em meados dos anos 1990, as exportações já eram um negócio promissor no SMSF e na mesma época avolumavam-se as denúncias nos principais jornais de Pernambuco sobre 
as péssimas condições de trabalho na fruticultura irrigada: trabalho infantil, transporte dos trabalhadores realizado de forma irregular, inexistência de dormitórios, refeitórios e água potável nos locais de trabalho, não pagamento de horas extras, trabalhadores sem carteira assinada, jornada de trabalho excessiva, etc. (SOUTO JR, 2011, 2013).

Foi nos anos 1990 que o Sindicato dos Trabalhadores e Trabalhadoras Rurais de Petrolina (STTR) iniciou o processo de organização dos assalariados na fruticultura com o objetivo de reivindicar direitos e melhorias nas condições de trabalho. Fundado em 27 de julho de 1963, o STTR teve sua história associada à expansão das organizações dos trabalhadores rurais no campo, na década de 1960, com a ajuda da Igreja Católica. Naquela época, o STTR reunia pequenos agricultores, pescadores, ribeirinhos e funcionava em uma pequena casa de propriedade da Diocese de Petrolina.

A organização dos assalariados rurais aconteceu nos anos 1990, após a falência da agroindústria e a ascensão da fruticultura. A Federação dos Trabalhadores na Agricultura do Estado de Pernambuco (Fetape) e a Confederação Nacional dos Trabalhadores na Agricultura (Contag) mantinham discussões com o objetivo de organizar os trabalhadores do SMSF e promover uma campanha salarial nos moldes da experiência da Convenção Coletiva dos Trabalhadores da Cana de Açúcar. A Fetape iniciou a organização dos assalariados da fruticultura em 1989. A primeira dificuldade foi interna, convencer os dirigentes, alguns pequenos produtores e empregadores, da necessidade de organizar os assalariados. Em 1992, iniciaram as negociações pelo fim do trabalho infantil, resultado de uma parceria com a Organização Internacional do Trabalho (OIT). O segundo passo foi regularizar a situação dos trabalhadores sem carteira de trabalho. No ano de 1994, apareceram os primeiros registros de greve no SMSF, em Santa Maria da Boa Vista e em Petrolina. A imprensa tratou da greve destacando a organização dos trabalhadores, que apresentaram uma pauta com 67 itens, e a desorganização do patronato ${ }^{4}$.

O sindicato patronal foi fundado em 1965 - Sindicato Rural de Petrolina - presidido por Geraldo Coelho, político da oligarquia local. Para Silva, esta iniciativa tinha o objetivo "de consolidar a influência de um grupo político local sobre os produtores, segundo as práticas do 'clientelismo' tradicional e, também, contrapor-se aos esforços da Igreja em organizar os trabalhadores rurais na região" (SILVA, 2001, p. 123). As dificuldades para iniciarem as primeiras negociações foram grandes, parte delas porque o empresariado estava dividido. De acordo com assessores e empresários, pôde-se perceber: a) parte significativa dos empresários estavam surpresos com a adesão dos trabalhadores às movimentações sindicais; $b$ ) as negativas de setores empresariais em dialogar com os trabalhadores se deviam a uma total falta de preparo para lidar com o conflito; c) o lócus da representação de interesses empresariais não estava no sindicato patronal, mas na Valexport, que manteve uma posição aberta e de promoção do diálogo.

A postura adotada pela Valexport pode ser entendida a partir da seguinte lógica: a) à frente da associação estavam os grandes produtores, que mantinham uma visão mais aberta 
do conflito, parte deles era composta de proprietários de grandes empresas que mantinham negócios em outros ramos da economia e em outros estados da federação; b) além disso, os mais envolvidos com a associação compreendiam o papel político que desempenhavam e a importância do diálogo; c) havia a percepção de que a continuidade da greve poderia estragar toda a produção, tendo em vista se tratar de frutas frescas; d) parte dos empresários temiam o dano que poderia ser causado à imagem da região no mercado externo, caso o SMSF fosse associado ao não cumprimento de direitos trabalhistas ${ }^{5}$; e) assessores contratados pela Valexport, com experiência nas negociações com o patronato da cana-de-açúcar da Zona da Mata, viram com bons olhos a proposta da Fetape em estabelecer uma CCT com negociações anuais e acreditavam que seria uma forma de evitar surpresas como interrupções da produção, além do mais, o acordo traria maior previsibilidade para o processo de produção; por fim, f) a CCT estendida para todo o SMSF tornaria o preço da força de trabalho uniforme, permitindo igualdade na competição entre os empresários da Bahia e de Pernambuco, que praticavam preços diferentes.

\begin{abstract}
Os produtores locais acharam primeiramente que isso era um movimento revolucionário, comunista, aquela coisa toda, era primeira impressão, a gente teve que desmistificar isso [...] isso era prova do regime do livre mercado, mas eles tiveram muito medo disso, e eles nunca tinham ouvido falar, eles conheciam, pelos contadores e advogados, a CLT, sabiam que existiam os direitos a serem cumpridos, com relação aos trabalhadores rurais [...] além da cultura da negociação foi a cultura dos direitos em si que estavam sendo postulados [...] a gente gastava muito tempo para nivelar o entendimento até interno ${ }^{6}$.
\end{abstract}

Diante das dificuldades e da importância que a questão tomou, houve a participação direta da Superintendência Regional do Trabalho e Emprego no Estado de Pernambuco ${ }^{7}$ (SRTE), que atuou como mediadora. Por outro lado, a intensificação das fiscalizações nas fazendas pela Gerência Regional do Trabalho e Emprego (GRTE), a pedido dos sindicatos, terminou por fortalecê-los diante dos trabalhadores.

Em 1994, foi assinada a primeira Convenção Coletiva de Trabalho dos Assalariados da Fruticultura. O sindicato patronal assinou a convenção para atender as exigências da lei. Até 2014 a Valexport coloca-se como organizadora da convenção (VALEXPORT, 2014). Nos anos seguintes, a mesma CCT passou a ser assinada por sindicatos de trabalhadores da Bahia

\footnotetext{
5 Não é objeto deste artigo, mas cabe mencionar que um dos principais selos de certificação de qualidade requeridos pelos grandes varejistas europeus como condição para que os fruticultores estejam habilitados para exportarem as frutas do Vale, o GLOBALGAP, requer o cumprimento da seguinte pauta, entre outras: a) disponibilidade de equipamentos e vestuário adequado para proteção contra os riscos à saúde; b) acesso fácil a banheiros limpos com ducha pelos trabalhadores; c) treinamento para utilização de equipamentos perigosos; e d) que os riscos devem ser claramente identificados por sinais sonoros (SELWYN, 2011: 1318).

6 Entrevista de José Otávio, advogado do patronato na CCT, à equipe de pesquisa. Recife, 30 de abril de 2012.

$7 \mathrm{Na}$ época era chamada de Delegacia Regional do Trabalho e a atual Gerência Regional do Trabalho e Emprego em Petrolina era chamada de Sub-Delegacia Regional do Trabalho em Petrolina.
} 
e Pernambuco ${ }^{8}$. Após a CCT, o STTR de Petrolina cresceu em número de filiados. Atualmente, o sindicato construiu uma sede própria com dois pavimentos, elevador, auditório, cozinha, inúmeras salas de escritórios com ar-condicionado e possuía três automóveis. A receita de 2014 do sindicato foi da ordem de $\mathrm{R} \$ 2.197 .715,98$ e o total das despesas foi $\mathrm{R} \$ 2.246 .026,07^{9}$. Até o início dos anos 1990, quando não tinha sido assinada nenhuma CCT, o STTR não tinha nem um bem: "o sindicato não tinha uma bicicleta pra andar, depois que a gente fechou, que foi feito o pagamento, os trabalhadores começaram a acreditar e pagar o sindicato, com menos de três meses a gente já tinha comprado um carro pra o sindicato" ${ }^{\prime 1}$.

É inevitável a conclusão de que o modelo de desenvolvimento no SMSF requereu, na hora devida, a organização dos trabalhadores capazes de negociar nos marcos da sociedade de mercado. O trabalhador como agente político é necessário à produção. Sem os trabalhadores organizados, as interrupções do processo de produção poderiam ser bastante custosas ao patronado. Não haveria necessidade de destruir as fábricas, como fizeram os luddistas. Bastaria parar a produção em qualquer fase para estragar o produto e colocar a perder o capital investido.

Portanto, compreendendo esse processo pela perspectiva da arena política, o empresariado disputou primeiro entre si, para decidir se incorporaria os trabalhadores ao jogo do desenvolvimento. Na perspectiva da fração dos que venceram a disputa, trazer os trabalhadores para dentro da arena seria assumi-los como um ator político importante, o que alteraria o status quo dos participantes, garantindo aos trabalhadores o direito de negociar. Reconhecê-los como sujeitos foi trazê-los para o centro da disputa política, mas diminuiria a possibilidade de ruptura, garantindo que a solução dos conflitos seria negociada. Para Sardan, os conflitos permitem a continuidade dos vínculos sociais, ao transformar as expressões de tensões sociais em válvulas de segurança, fornecendo procedimentos ritualizados para suas resoluções (SARDAN, 2005).

As consequências desse processo podem ser vistas nas negociações das CCT. Mota Silva (2014) analisou as CCTs de 1994 até a de 2013 e concluiu que os trabalhadores vivenciaram vitórias e também derrotas. No bojo das cláusulas reivindicadas, havia direitos já adquiridos e, em alguns casos, derrotas para os trabalhadores, como a introdução do banco de horas. Rodrigues (2009), chegou à mesma conclusão sobre os direitos já existentes, mas que não eram cumpridos. As convenções teriam o sentido de, por meio da mobilização e assinatura, reafirmar esses direitos e legitimar os trabalhadores nas mesas de negociações.

Em artigo recente analisamos os resultados das negociações das convenções desde 2004, o resultado da análise foi que as CCTs abriram um caminho de direitos para os assalariados

8 Participam da construção e negociação da convenção coletiva, os Sindicatos de Trabalhadores Rurais de: Petrolina, Santa Maria da Boa Vista, Belém do São Francisco, Lagoa Grande e Cabrobó, todos em Pernambuco, e Juazeiro, Casa Nova, Sento-Sé, Sobradinho, Curaçá e Abaré, na Bahia, Federação dos Trabalhadores Rurais de Pernambuco, Federação dos Trabalhadores na Agricultura no Estado da Bahia, Confederação Nacional dos Trabalhadores na Agricultura e Central Única dos Trabalhadores (CUT).

9 Relatório de Contas STR-Petrolina (Exercício 2014). Dados obtidos na Assembleia Geral Extraordinária do STR, no dia 22 de junho de 2015, pelo pesquisador Guilherme José Mota Silva.

10 Entrevista com uma liderança sindical realizada em Petrolina, em 2011. 
da fruticultura. Mas, ao longo do tempo, os ganhos ficaram aquém da capacidade de barganha dos sindicatos, os ganhos em relação ao salário mínimo, por exemplo, foram menores ao longo do tempo, tendo em vista o fato de que o sindicato se tornou mais robusto e com capacidade de contratar assessorias. Demonstrou-se que houve ganhos reais de salário acima do mínimo oficial. Contudo, "a hipótese é a de que os sindicatos se habituaram à rotina burocrática desde a primeira CCT, tendo crescido enormemente em tamanho e arrecadação e perdendo o protagonismo junto às bases (SOUTO JR; MOTA SILVA; ALMEIDA, 2015, p. 23-24).

\section{Considerações finais}

Para o entendimento do desenvolvimento do SMSF, foi utilizado o conceito de cluster de Porter (1998) e arena de Sardan (2005), perspectiva que ressalta a construção de relações sociais e do modelo de desenvolvimento sob a ótica da interação e conflito dos atores sociais. Num primeiro momento, o Estado e suas agências assumem protagonismo ao construir a infraestrutura, modelar e direcionar os investimentos com o objetivo de incentivar a agroindústria. À medida que o Estado avançou no desenho do projeto de desenvolvimento, o estímulo à dinâmica da iniciativa privada se deu na forma de recrutamento de produtores situados no polo mais dinâmico da agricultura moderna brasileira, as cooperativas (MENDONÇA, 2010).

$\mathrm{O}$ associativismo trouxe uma racionalidade que dinamizou as relações comerciais ao mesmo tempo em que iam se conformando no SMSF as características de um cluster, que demanda uma diversidade de atores sociais competindo em cooperação. As formas associativas dinamizaram a iniciativa privada integrando as ações e unificando os interesses privados comerciais. A constituição de um novo sujeito político ligado aos fruticultores, à Valexport, deu unidade política ao núcleo mais dinâmico da fruticultura irrigada, pautando a agenda política mais geral e reordenando as prioridades das agências estatais.

A insurgência dos trabalhadores nos anos 1990 redefiniu o clima de relativa harmonia no arranjo político entre o Estado, as agências estatais e os empresários. O reconhecimento dos trabalhadores como sujeito aconteceu após a unidade dos interesses políticos do empresariado pela Valexport. A entrada dos trabalhadores para a arena conferiu-lhes o status de sujeito ao mesmo tempo em que coroou o protagonismo da Valexport, no que chamamos "modelo de desenvolvimento", ao garantir um canal de resolução de conflitos entre trabalhadores e empresários na forma da CCT, que é mediada pelos órgãos fiscalizadores do Estado, conferindo um incontestável atestado de boas relações entre capital e trabalho, além de garantir o fato primordial para a produção do agronegócio, a previsibilidade.

\section{Referências}

BLOCH, D. As frutas amargas do velho chico: irrigação e desenvolvimento no vale do São Francisco. São Paulo: Livros da Terra, Oxfam, 1996. 
CARNEIRO, Marcelo S. Práticas, discursos e arenas: notas sobre a socioantropologia do desenvolvimento. Sociologia \& Antropologia, Rio de Janeiro, v. 2, n. 4, p. 129-158, 2012.

CAVALCANTI, J. S. B. Frutas para o mercado global. Estudos Avançados, São Paulo, v. 11, n. 29, p. 79-93, 1997.

CAVALCANTI, J. S. B. Globalização, novas regiões de produção agrícola e desigualdades sociais. Caderno CRH, Salvador, v. 24, n. 25, p. 109-121, jan./dez. 1996.

CAVALCANTI, J. S. B.; MOTA, D. M. da; SILVA, C. B. da. Os trabalhadores no contexto da globalização dos alimentos. São Paulo: EDUSP, 2003.

CELLARD, André. A análise documental. In: POUPART, Jean; DESLAURIES, Jean-Pierre; GROULX, Lionel-H.; (org.). A pesquisa qualitativa: enfoques epistemológicos e metodológicos. Petropólis: Vozes, 2010. p. 295-316.

DAMIANI, O. Beyond market failures: irrigation, the state, and non-traditional agriculture in Northeast Brazil. 1999. Tese (Doctor of Philosophy) - Department of Urban Studies and Planning, Massachusetts Institute of Technology, Cambridge, 1999.

DUARTE, Jorge. Prosa com Eliseu. Brasília, DF: Embrapa, 2018.

FLICK, U. Introdução à Pesquisa Qualitativa. Porto Alegre: Artmed, 2009.

GOMES, R. Upgrading without exclusion: lessons from SMEs in fresh fruit clusters in Brazil, unpublished octoral thesis. Massachusetts: MIT Department of Urban Studies and Planning, 2004.

GILL, R. Análise de discurso. In: Bauer, M.W.; Gaskell, G. Pesquisa Qualitativa com Texto Imagem e Som: Um manual prático. Petrópolis, RJ: Vozes, 2002. p. 244- 270.

GOLDENBERG, Mírian. A arte de pesquisar: como fazer pesquisa qualitativa em ciências sociais. Rio de Janeiro: Editora Record, 2004.

MEDEIROS, Leonilde Servolo de. Trabalhadores rurais, agricultura familiar e organização sindical. São Paulo em Perspectiva, São Paulo, v. 11, n. 2, p. 65-72, abr./jun. 1997.

MENDONÇA, Sônia Regina de. O patronato rural no Brasil recente (1964-1993). Rio de Janeiro: Editora da UFRJ, 2010.

MOTA SILVA, G. J. Frutos do desenvolvimento: as contradições do capital e a construção de uma política sindical de assalariados rurais da fruticultura irrigada no submédio São Francisco. 2014. Trabalho de Conclusão de Curso (Graduação em Ciências Sociais) - Universidade Federal do Vale do São Francisco, Juazeiro, 2014.

NOVAES, R. Reyes. Continuidades e rupturas no sindicalismo rural. In: BOITO, Armando (org.). O sindicalismo brasileiro nos anos oitenta. Rio de Janeiro: Paz e Terra, 1991. p. 171-196.

OLIVEIRA, Francisco de. Elegia para uma re(li)gião: Nordeste, Sudene, Planejamento e Conflito de Classes. Rio de Janeiro: Paz e Terra, 1981.

PIMENTEL, Alessandra. O método da análise documental: seu uso numa pesquisa historiográfica. Cadernos de Pesquisa, São Paulo, n. 114, p. 179-195, 2001.

PORTER, Michael E. Clusters and the New Economics of Competition. Havard Business Review, Massachusetts, p. 1-31. nov./dez. 1998. Disponível em: https://hbr.org/1998/11/clusters-and-the-new-economics-of-competition. Acesso em: 25 mar. 2019.

RODRIGUES, V. de O. Globalização da agricultura e mudança no mundo do trabalho: os trabalhadores rurais do Vale do São Francisco. 2009. Trabalho de Conclusão de Curso (Graduação em Ciências Sociais) - Universidade Federal de Pernambuco, Recife, 2009.

SARDAN, Jean-Pierre Olivier. Antropology and development: understanding contemporary social changes. London : Zed books, 2005.

SELWYN, Ben. Globalized Horticulture: The Formation and Global Integration of Export Grape Production in North East Brazil. Journal of Agrarian Change, v. 10, n. 4, p. 537-563, out. 2010. 
SELWYN, Ben. Institutions, Upgrading and Development: Evidence From North East Brazilian Export Horticulture. Competition \& change, v. 12, n. 4, p. 377-396, dez. 2008.

SELWYN, Ben. The global retail revolution, fruiticulture and economic development in north-east Brazil. Review of International Political Economy, v. 20, n. 1, p. 153-179, 2013.

SELWYN, Ben. Labour flexibility in export horticulture: a case study of northeast Brazilian grape production. Journal of Peasant Studies, v. 36, n. 4, p. 761-782, 2009.

SILVA, Pedro Gama da. Articulação dos interesses públicos e privados no pólo Petrolina-Pe/Juazeiro-Ba: em busca de espaço no mercado globalizado de frutas frescas. 2001. Tese (Doutorado em economia) - Instituto de Economia, Universidade Estadual de Campinas, Campinas, 2001.

SILVA, Pedro Gama da. Dinâmica e crise da fruticultura irrigada no Vale do São Francisco. In: SILVA, Aldenor Gomes da; CAVALCANTI, Josefa Salete B.; WANDERLEY, Maria de Nazareth B. (org.). Diversificação dos espaços rurais e dinâmicas territoriais no Nordeste do Brasil. João Pessoa: Editora Zarinha Centro de Cultura, 2009. p. 69-95.

SOUTO JR, J. F. O Vale Encantado do São Francisco: desenvolvimentismo e sindicalismo rural (1990 - 2008). REDD - Revista Espaço de Diálogo e Desconexão, Araraquara, v. 3, n. 2, p. 1-13, jan/jul. 2011.

SOUTO JR, J. F. Se parar, a fruta apodrece: fordismo e sindicatos no Vale do São Francisco. REED - Revista Espaço de Diálogo e Desconexão, Araraquara, v. 7, n. 1, p. 1-20, jul./dez. 2013.

SOUTO JR, J. F; MOTA SILVA, G. J. M. O lugar da ausência: luta de classes e direitos na fruticultura irrigada do São Francisco. In: ENCONTRO NACIONAL DA ASSOCIAÇÃO BRASILEIRA DE ESTUDOS DO TRABALHO, 13, 2013, Curitiba. Anais do XIII Encontro Nacional da Associação Brasileira de Estudos do Trabalho - ABET. Curitiba: UFPR, 2013. p. 76-102.

SOUTO JR, J. F.; MOTA SILVA, G. J.; ALMEIDA, Camilla. Frutos do desenvolvimento: trabalho, ação coletiva e sindicalismo no Submédio São Francisco. In: ENCONTRO NACIONAL DA ASSOCIAÇÃO BRASILEIRA DE ESTUDOS DO TRABALHO, 14, 2015, Campinas. Anais do XIV Encontro Nacional da Associação Brasileira de Estudos do Trabalho - ABET. Campinas: Unicamp, 2015. p. 69-95.

VALEXPORT. O potencial do Vale do São Francisco Brasil. Petrolina-PE, 2013.

VALEXPORT. Há 26 anos unindo forças para o desenvolvimento do Vale do São Francisco e da fruticultura brasileira. Petrolina-PE, 2014.

Recebido em: 28/05/2018 